\title{
Trend analysis of cost efficiency for the pharmaceutical industry: A DEA approach
}

\author{
Teg Alam ${ }^{a *}$ and Rupesh Rastgi ${ }^{b}$
}

${ }^{a}$ College of Business Administration, Prince Sattam Bin Abdulaziz University, Al Kharj, Kingdom of Saudi Arabia ${ }^{b}$ Department of Business Administration, Azad Technical Campus, Lucknow - 226002, Uttar Pradesh, India

\section{H R O N I C L E}

Article history:

Received: December 25, 2018

Received in revised format: January 2, 2019

Accepted: January 28, 2019

Available online:

January 28, 2019

Keywords:

Pharmaceutical industry

India

Data Envelopment Analysis

Efficiency and Slack

\begin{abstract}
This paper evaluates the efficiency of five Indian pharmaceutical Industries using Data Envelopment Analysis (DEA) approach. The paper uses Net Block, Cash and Bank Balance, Share Capital, Reserve and Surplus, Secure Loan and Unsecured Loan as input variables and Investments and 'Loans and Advances' as output variables. In this study, the Basic Radial Models input oriented with Constant Returns to scale (CRS) are used to estimate the efficiency of pharmaceutical Industries. The DEA tool assists the administrators to identify the inefficient measures and take necessary actions for improvement. The results are indicative of the scenario that changed patent laws in India are not detrimental to the financial and overall health of Indian pharmaceutical companies in general. The Indian pharmaceutical companies have suitably modified their business model to cope up with the changed legal environment. It is a positive sign for all Indian pharmaceutical companies that they are dynamic in management and operational policies to face any new situation and shall flourish more in the coming days.
\end{abstract}

\section{Introduction}

The Pharmaceutical industry plays an important role for the development of the economy in developing countries and it is the biggest producer and exporter of the generic drugs across the world. Indian pharmaceutical industry fulfills 70 per cent of India's demand of drug usages and has exported drugs to the rest of the world. As per global standards the production cost of Indian pharmaceutical industry is very low and it is approximately 70 percent less than US and Europe. In 2013 the value of Indian pharmaceutical industry was US\$22 billion and presently it is growing at the rate of 8-9 per cent annum. At the time of Indian independence, the Indian pharmaceutical market was dominated by the large multinational companies which were in command of about 70 percent of the Indian market. The Indian Patent Act 1970 greatly assisted in the growth of the domestic pharmaceutical companies. The Patent Act 1970, had proviso for process patents for pharmaceuticals and agro-chemical products. This provision greatly helped the Indian pharmaceutical industry which was free to make any patented molecule by reverse engineering the manufacturing process. Indian pharmaceutical industry supplied patented drugs at a fraction of the original inventors/manufacturer cost. Now the domestic pharmaceutical companies have emerged as the world's leader for generic drugs production. The industry presently makes over $10 \%$ of the global drug production. After getting assistance of the Indian Patent Act 1970, the conditions of the

\footnotetext{
* Corresponding author.

E-mail address: t.alam@psau.edu.sa (T. Alam) 
Indian pharmaceutical industry has been improved. The Indian companies also gained expertise in reverse engineering. The advantage/protection of the Indian Patent Act 1970 to Indian Pharmaceutical Industry continued till 1994, when India became a member country of WTO. Being a founder member of WTO, India was required to honor the TRIPS agreement. TRIPS agreement re-introduced product patent in India. However, India was given transition period of ten years, (till the end of 2004) for making their patent policies TRIPS compliant. The present study is an attempt to know and compare the financial performance of select pharmaceutical companies in different legal regimes. This study is based on the secondary data taken from annual reports of Aurbindo, Cipla, Lupin, erstwhile Ranbaxy and Dabur. Selected items have been taken from the balance sheet of the companies and they are compared and measured in the PRE TRIPS period and POST TRIPS period. The data for PRE TRIPS period is taken from 2001 to 2004 and for POST TRIPS period it is 2005-2011.

In the present study, data envelopment analysis (DEA) has been used for measuring the efficiency and ranking of the five Indian Pharmaceutical Companies. The method has been widely used to measure the relative efficiency of companies in India and in the rest of the worlds. Some previous studies on the India have also used various extensions of DEA techniques to measure the relative efficiency of similar units in various industry. Chaudhuri and Das (2006) implemented some DEA methods to estimate the efficiency of the firms from 1990 to 2001 . The result of the study indicates that the mean efficiency scores of the industry improved over the period 1999-2001 versus the period 1990-1998.

Saranga and Phani (2009) applied DEA models reported a correlation between internal efficiencies and higher growth rates. Mazumdar et al. (2009) used DEA technique to access the output and input efficiencies of the IPI. Saranga and Banker (2010) computed productivity and technical changes of some pharmaceutical firms from 1994 to 2003 and concluded that high R\&D strength and broad new product portfolios of MNCs had improved technical capabilities and productivity in the industry. Pannu et al. (2011) applied DEA models to examine the relative efficiency and productivity of the IPI between 1998 and 2007. As well, Kumar and Arora (2012), Mahajan et al. (2014), Alam and Rastogi (2011, 2014, 2016, 2017a,b,c) studied about Indian Pharmaceutical Industries. Alam (2018) studied the efficiency of the hospitals in the Saudi Arabia. Finally, Aalm (2017) applied DEA to compare the efficiency of some colleges in the Kingdom of Saudi Arabia using DEA technique.

\section{Material and Methods}

Let $x_{i j}$ be the inputs for decision-making unit $j$ with $i=1, \ldots, m$ and $y_{r j}$ be the outputs of the same units with $r=1, \ldots, s$ and $j=1, \ldots, n$ and let $u_{i}$ and $v_{j}$ be the dual variables associated with $x_{i}$ and $y_{j}$, respectively. The proposed DEA model is formulated as follows,

$$
\begin{array}{ll}
\max & z=\frac{\sum_{r=1}^{s} u_{r} y_{r .} .}{\sum_{i=1}^{m} v_{i} x_{i .}} \\
\text { subject to } & \frac{\sum_{r=1}^{s} u_{r} y_{r j}}{\sum_{i=1}^{m} v_{i} x_{i j}} \leq 1 . \quad x_{i j}, y_{i j \geq 0}
\end{array}
$$

Model (1) is one of the primary DEA methods solved $j$ times to detect the relative efficiencies of various units. Charles et al. (1979) proposed a simple modification of the objective function to convert (1) into a simple linear programming problem as follows, 


$$
\begin{array}{ll}
\max & z=\sum_{r=1}^{s} u_{r} y_{r} . \\
\text { subject to } & \frac{\sum_{r=1}^{s} u_{r} y_{r j}}{\sum_{i=1}^{m} v_{i} x_{i j}} \leq 1, \quad \sum_{i=1}^{m} v_{i} x_{i .}=1, \quad u_{r}, v_{i} \geq 0, \quad j=1, \ldots, n
\end{array}
$$

Problem (2) has been extensively implemented for years and the results have been accepted as a tool for computing the relative efficiencies of different units. There are literally different extensions of DEA methods such as input or output oriented models and they are solved based on whether there is a control on the output or the input parameters. The propsoed model of this paper uses 6 inputs and 2 outputs. The data used in this study covers five Pharmaceutical Industries of the India. The data for this study (Year 2001-2011) is obtained from the Annual reports of the pharmaceutical companies. This study uses DEA Software (DEAOS) to calculate the efficiency scores of hospitals by 'Basic Radial Models input oriented with Constant Returns to scale (CRS).

\section{Inputs}

- Net Block: Net block includes the assets which are worth to the company. Net block is calculated as Gross Block minus accumulated depreciation on assets. Gross block is sum of all assets of the company valued at its cost of acquisition.

- Cash and Bank Balance: Cash includes cash in hand at the time of book closure and includes cash in checking, saving and short term investment accounts. Bank balance includes the sum of money in a bank account at a specific time.

- Share Capital: Capital collected by a joint stock company for business operations is share capital. It is the capital which is collected from shareholders. The share capital of company may change because each time a company sells new share the amount of share capital increases.

- Reserve and Surplus: At the end of the financial year part profit of the company may be transferred to reserves. The balance in profit/loss account is considered as surplus. The amount of premium received if shares are issued at a premium to the encountered value is also presented under the head reserves and surplus. The excess of income over expenditure is acknowledged as surplus.

- Secure Loan: It includes loans and advances raised by the company after creating a charge on its assets. Debentures are also included in this category.

- Unsecured Loan: It includes loans and advances raised by the company without creating a charge on its assets. Fixed deposits received from general public are also included in this category.

\section{Outputs}

- Investments: Investment includes all investments made by the company which cannot be converted in cash in a period of less than one year. Companies may invest their surplus fund Government securities, debt instruments or equities of the corporate sector.

- Loans and Advances: Loans include any loan given by the company to its sister concerns, employees and directors. If surplus fund remains available with the company than it gives loans. Advances are given for a specific purpose against which goods or services are to be received in near future.

\section{Result and Discussion}

Table 1 demonstrates the results of the implementation of the DEA method for measuring the relative efficiencies of five pharmaceutical firms. 
Table 1

Efficiencies of DMUs

\begin{tabular}{cccccc}
\hline Year & DMU1 & DMU2 & DMU3 & DMU4 & DMU5 \\
\hline 2001 & $\mathbf{0 . 7 8 8}$ & 1 & 1 & $\mathbf{0 . 7 9 5}$ & $\mathbf{0 . 9 5 4}$ \\
2002 & 1 & 1 & 1 & 1 & 1 \\
2003 & 1 & 1 & 1 & 1 & 1 \\
2004 & 1 & 1 & 1 & $\mathbf{0 . 6 8 9}$ & 1 \\
2005 & 1 & 1 & 1 & 1 & 1 \\
2006 & 1 & 1 & 1 & 1 & 1 \\
2007 & 1 & 1 & $\mathbf{0 . 5 4 9}$ & 1 \\
2008 & 1 & 1 & 1 & 1 & 1 \\
2009 & 1 & 1 & 1 & 1 & 1 \\
2010 & 1 & 1 & 1 & 1 & 1 \\
2011 & 1 & 1 & & & 1 \\
\hline
\end{tabular}

For the Pharmaceutical companies that are efficient efficiency scores equal to 1 . These companies are efficient in utilizing their resources to produce outputs. In the year 2001 DMU1, DMU4 and DMU5 are closer to 1 which shows that these Pharmaceutical companies could improve their performance and become efficient in near future. The analysis suggests that almost all Pharmaceutical Industries were efficient in utilizing their resources.

\subsection{Input slacks and Output slacks}

Since all DMUs are efficient except 2001, 2005 and 2006. Therefore, Input slacks and Output slacks for the year 2001, 2005 and 2006 are given in Table 2 as follows,

Table 2

Input slacks for the year 2001 (in million Rs.)

\begin{tabular}{|c|c|c|c|c|c|c|}
\hline & Input1 & Input2 & Input3 & Input4 & Input5 & Input6 \\
\hline DMU1 & 330.255 & 0.991 & 0 & 788.095 & 96.508 & 480.536 \\
\hline DMU2 & 0 & 0 & 0 & 0 & 0 & 0 \\
\hline DMU3 & 0 & 0 & 0 & 0 & 0 & 0 \\
\hline DMU4 & 1971.344 & 382.833 & 0 & 1604.545 & 114.988 & 515.138 \\
\hline DMU5 & 13969.96 & 1935.616 & 0 & 2646.485 & 0 & 15467.36 \\
\hline
\end{tabular}

From the Table 2, it is observed that DMU1 needed slacks for Input 1, Input 2, Input 4, Input 5 and Input 6 are 330.255, 0.991, 788.095, 96.508 and 480.536, respectively to achieve the desirable efficiency. DMU4 needed slacks for Input1 Input2, Input4, Input5 and Input6 are 1971.344, 382.833, $1604.545,114.988$ and 515.138, respectively to achieve the desirable efficiency. In addition, DMU5 needed slacks for Input1 Input2, Input4 and Input6 are 13969.96, 1935.616, 2646.485 and 15467.36 respectively to achieve the highest efficiency.

Table 3

Output slacks for the year 2001 (in million Rs.)

\begin{tabular}{lcc}
\hline & Output1 & Output2 \\
\hline DMU1 & 0 & 0 \\
DMU2 & 0 & 0 \\
DMU3 & 0 & 0 \\
DMU4 & 0 & 720.032 \\
DMU5 & 2187.082 & 0 \\
\hline
\end{tabular}

It is evident from Table 3, DMU 4 and DMU 5 needed slacks for output 2 and output 1 are 720.032 and 2187.082 respectively for achieving the target efficiency.

Table 4

Input slacks for the year 2005 (in million Rs.)

\begin{tabular}{|c|c|c|c|c|c|c|}
\hline & Input1 & Input2 & Input3 & Input4 & Input5 & Input6 \\
\hline DMU1 & 0 & 0 & 0 & 0 & 0 & 0 \\
\hline DMU2 & 0 & 0 & 0 & 0 & 0 & 0 \\
\hline DMU3 & 0 & 0 & 0 & 0 & 0 & 0 \\
\hline DMU4 & 0 & 461.794 & 246.873 & 554.859 & 1834.185 & 3147.817 \\
\hline DMU5 & 0 & 0 & 0 & 0 & 0 & 0 \\
\hline
\end{tabular}


From Table 4, it is observed that DMU4 needed slacks for Input 2, Input 3, Input 4, Input 5 and Input6 are $461.794,246.873,554.859,1834.185$ and 3147.817 respectively for achieving the efficiency.

Table 5

Output slacks for the year 2005 (in million Rs.)

\begin{tabular}{lcc} 
& Output1 & Output2 \\
\hline DMU1 & 0 & 0 \\
DMU2 & 0 & 0 \\
DMU3 & 0 & 0 \\
DMU4 & 0 & 0 \\
DMU5 & 0 & 0 \\
\hline
\end{tabular}

Table 5 shows that none of the DMUs needs any slacks values.

Table 6

Input slacks for the year 2007 (in million Rs.)

\begin{tabular}{|c|c|c|c|c|c|c|}
\hline & Input1 & Input2 & Input3 & Input4 & Input5 & Input6 \\
\hline DMU1 & 0 & 0 & 0 & 0 & 0 & 0 \\
\hline DMU2 & 0 & 0 & 0 & 0 & 0 & 0 \\
\hline DMU3 & 3559.883 & 7073.538 & 0 & 0 & 7826.534 & 0 \\
\hline DMU4 & 0 & 0 & 0 & 0 & 0 & 0 \\
\hline DMU5 & 0 & 0 & 0 & 0 & 0 & 0 \\
\hline
\end{tabular}

From the Table 6, we have perceived that DMU3 needed slacks for Input 1, Input 2, and Input 5 are $3559.883,7073.538$ and 7826.534 , respectively for achieving the effectiveness.

Table 7

Output slacks for the year 2007 (in million Rs.)

\begin{tabular}{lcc}
\hline & Output1 & Output2 \\
\hline DMU1 & 0 & 0 \\
DMU2 & 0 & 0 \\
DMU3 & 8160.021 & 0 \\
DMU4 & 0 & 0 \\
DMU5 & 0 & 0 \\
\hline
\end{tabular}

From the Table 7, it is observed that DMU3 needed slack for Output1 is 8160.021 for achieving the efficiency. From the above Tables, we have observed that none of the efficient pharmaceutical companies had any slacks. Slacks exist only for those pharmaceutical companies determined as inefficient but slacks are considered only the remaining lots of inefficiencies; after appropriate reductions in inputs or increases in outputs, if a DMU cannot reach the efficiency border, slacks are required to push the DMU to the target.

\section{Conclusion}

This study has used the DEA technique to assess the efficiency of five Indian Pharmaceutical companies. The results have indicated that almost all Pharmaceutical companies were efficient in terms of Basic Radial Models input oriented with Constant Returns to scale (CRS). The results have suggested that the Pharmaceutical Industries were efficient in utilizing their resources to produce all the defined outputs. The efficiency scores have indicated whether Pharmaceutical Industries needs improvement or not. This can be correlated with 'either decreasing the inputs or increasing the outputs' or vice versa. The results are indicative of the scenario that changed patent laws in India are not detrimental to the financial and overall health of Indian pharmaceutical companies in general. The Indian pharmaceutical companies have suitably modified their business model to cope up with the changed legal environment. It is a positive sign for all Indian pharmaceutical companies that they are dynamic in management and operational policies to face any new situation and shall flourish more in the coming days. 


\section{References}

Alam, T., \& Rastogi, R. (2011). The Indian pharmaceutical industry: The empirical study. VSRD International Journal of Business and Management Research, 1(7), 408-415.

Alam, T., \& Rastogi, R. (2014). The Indian pharmaceutical industry transition to trade-related aspects of intellectual property rights (TRIPS) compliant patent regime: A case study. VSRD International Journal of Business and Management Research, 4(12), 331-338.

Alam, T., \& Rastogi, R. (2016). Pre TRIPS, post TRIPS patent regime and the Indian pharmaceutical industry: An empirical study. Indian Journal of Science and Technology, 9(9), 1-7.

Alam, T. (2017a). The efficiency of colleges: Using DEA - A non-parametric approach. International Journal of Mechanical Engineering \& Technology (IJMET), 8(8), 1004-1008.

Alam, T. (2017b). Efficiency of colleges at Prince Sattam Bin Abdulaziz University, Al Kharj (A Comparative Study using Data Envelopment Analysis). Journal of Engineering and Applied Sciences, 12(15), 3899-3904.

Alam, T., \& Rastogi, R. (2017c). Agreement on trade-related aspects of intellectual property and the pharmaceutical industry: An empirical study. International Journal of Mechanical Engineering and Technology 8(9), 369-377.

Alam, T. (2018). Evaluating efficiency of hospitals in the Kingdom of Saudi Arabia: DEA: An operational research technique approach. International Journal of Mechanical Engineering and Technology, 9(10), 1400-1405.

Banker, R.D., Charnes, A., \& Cooper, W.W. (1984). Some models for the estimation of technical and scale inefficiencies in Data Envelopment Analysis. Management Science, 30, 1078-1092.

Charnes, A., Cooper, W. W., \& Rhodes, E. (1979). Measuring the efficiency of decision-making units. European Journal of Operational Research, 3(4), 339-338.

Chaudhuri, K., \& Das, S. (2006). WTO, the TRIPS and Indian pharmaceutical industry. Journal of Quantitative Economics, 4(1), 97-110.

Kumar, S. and Arora, N. (2012). Evaluation of technical efficiency in Indian sugar industry: an application of full cumulative data envelopment analysis. Eurasian Journal of Business and Economics, 5(9), 57-78.

Mahajan, V., Nauriyal, D.K. \& Singh, S.P. (2014). Technical efficiency analysis of the Indian drug and pharmaceutical industry: A Non-parametric Approach. Benchmarking: An International Journal, 21(5), 734-755.

Mazumdar, M., \& Rajeev, M. (2009). Comparing the efficiency and productivity of the Indian pharmaceutical firms: A Malmquist-Meta-Frontier approach. International Journal of Business and Economics, 8(2), 159-181.

Mazumdar, M., Rajeev, M., \& Ray, S. C. (2009). Output and input efficiency of manufacturing firms in India: A case of the Indian pharmaceutical sector. Institute for Social and Economic Change.

Pannu, H.S., Kumar, U.D., \& Farooquie, J.A. (2011). Efficiency and productivity analysis of Indian pharmaceutical industry using data envelopment analysis. International Journal of Operational Research, 10(1), 121-136. ttp://dx.doi.org/10.1504/IJOR.2011.037266

Saranga, H., \& Phani, B. V. (2009). Determinants of operational efficiencies in the Indian pharmaceutical industry. International Transactions in Operational Research, 16(1), 109-130.

Saranga, H., \& Banker, R. D. (2010). Productivity and technical changes in the Indian pharmaceutical industry. Journal of the Operational Research Society, 61(12), 1777-1788.

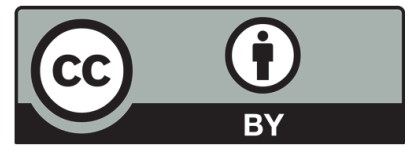

(C) 2019 by the authors; licensee Growing Science, Canada. This is an open access article distributed under the terms and conditions of the Creative Commons Attribution (CC-BY) license (http://creativecommons.org/licenses/by/4.0/). 